\title{
Study on Stack Effect of Stairwell by Numerical Model of Leakage Flow through Gap of Door
}

\author{
Jung-Yup Kim, Ji-Seok Kim \\ Fire Research Center, Korea Institute of Construction Technology, Goyang-Si, South Korea \\ Email: jykim1@kict.re.kr
}

Received August 21, 2013; revised September 21, 2013; accepted September 28, 2013

Copyright (C) 2013 Jung-Yup Kim, Ji-Seok Kim. This is an open access article distributed under the Creative Commons Attribution License, which permits unrestricted use, distribution, and reproduction in any medium, provided the original work is properly cited.

\begin{abstract}
Since stack effect that occurs in high-rise buildings has an effect on the indoor environment of the buildings, energy loss and smoke control in case of a fire, there is a need to conduct research on this. For an analysis of the stack effect, analysis methods on the leakage flow through gap of interior door shall be formulated. Until now, studies related to the gap leakage flow in buildings have mainly analyzed flow field and pressure in the buildings one-dimensionally using pressure difference-leakage flowrate relations of Orifice Equation and a network numerical analysis algorithm that assumes each compartment in the buildings as a single point. In this study, the Momentum Loss Model which enables pressure drop to be proportional to the flow velocity through the gap of door in computational domain of 3-dimensional numerical analysis was proposed to reflect the gap flow phenomenon effectively in 3-dimensional numerical analysis. Using the proposed model, 3-dimensional numerical analysis of the stack effect on the stairs in buildings was performed, and the effects of separation door and lobby between stair and accommodation on the stack effect were investigated.
\end{abstract}

Keywords: Stack Effect; Leakage Flow; Gap of Door; Momentum Loss Model; Separation Door; Numerical Analysis

\section{Introduction}

In buildings, there exist the gaps between compartments such as those of doors and windows, and a flow occurs through these gaps. Since the flow affects various heat flow phenomena that occur in buildings, analysis methods are needed for this. As for the stack effect, ventilation design, air tightness, energy analysis and smoke control in case of a fire, the gap flow has been considered as an important factor.

In particular, the stack effect has been found to affect many phenomena within high-rise buildings such as smoke flow in case of a fire, indoor environment, energy loss and elevator malfunction. The theoretical pressure difference due to the stack effect can be calculated by Equation (1).

$$
\Delta P_{s t}=g \Delta \rho(N-h)=g \rho_{o}\left(\Delta T / T_{i}\right)(N-h)
$$

where $g$ is the acceleration of gravity $\left(\mathrm{m} / \mathrm{s}^{2}\right), h$ is the height of the measuring point (m), $N$ is the neutral pressure level $(\mathrm{m}), T_{i}$ is the room temperature $(\mathrm{K})$ and $\rho_{o}$ is the outdoor air density $\left(\mathrm{kg} / \mathrm{m}^{3}\right)$.

With respect to the stack effect in high-rise buildings, continuous research is being done internationally. The pressure fields in high-rise office buildings were presented and their characteristics were investigated using the index of Thermal Draft Coefficient [1]. Through the field measurements and analyses in two high-rise residential buildings, the characteristics of pressure distribution caused by stack effect in high-rise building were presented and solution for stack effect problems using "airlock doors" was proposed [2]. The architectural elements that affect the stack effect in a high-rise building were selected and the effect of the elements was quantitatively analyzed by simulation of network model [3].

In the analysis that includes gap leakage flow of the building that has a large influence on the stack effect, pressure difference-leakage flowrate relations around the gap of door is usually represented by Equation (2).

$$
Q=f(\Delta p)
$$

where $Q$ is the leakage flow rate and $\Delta p$ is the pressure difference before and after the gap respectively.

In relation to the pressure difference and leakage flowrate relations, a lot of researches were conducted in the $70 \mathrm{~s}$ to $90 \mathrm{~s}$, focusing on derivation of theoretical equation and experimental data. Through dimensional analysis and 
experimental data on the gap leakage flow of compartments, equations and coefficients between related factors such as the pressure difference, flowrate and Reynolds number were derived [4]. And based on these studies and theoretical analysis, the quadratic equation between the pressure difference and flow rate was presented, and an experiment for the estimation of coefficients was performed [5].

Meanwhile, the Gap Method that can predict the leakage flow in the gap of door with various structures was presented, and equation to establish the relationship between dimensionless flow rate and dimensionless pressure difference according to three types of pressure ranges around the door was derived for a comparison with experimental data [6].

In addition, there was little difference in calculation results between the simple Orifice Equation as shown in Equation (3) and Gap Method in case of the gap flow of doors in buildings [7].

$$
Q=C A \sqrt{\frac{2 \Delta p}{\rho}}=C_{t} \sqrt{\Delta p}
$$

where $Q$ is the leakage flow rate, $\Delta p$ is the pressure difference before and after the gap, $C$ is the flow coefficient, $A$ is the gap area, and $\rho$ is the density of air respecttively.

As described above, studies related to the gap leakage flow in buildings have mainly analyzed flow and pressure field in the buildings one-dimensionally using the pressure difference-leakage flowrate relation as in Equation (3) and network numerical analysis algorithm that assumes each compartment in the buildings as a single point.

Meanwhile, 3-dimensional flow analysis technique has been greatly developed based on the computational fluid dynamics and applied to various areas of buildings. However, in case the leakage flow of the gap is included, cross-sectional area of the gap is much less compared with other areas of the building, which has led to a lot of difficulties in grid generation and 3-dimensional flow analysis. Thus, methods for 3-dimensional analysis that includes the gap are deemed necessary.

As before, the leakage flow through the gap of door can be set with the relation of the pressure difference around the door and gap flow rate, and this relationship in computational fluid dynamics can be reflected as the Momentum Loss Model in the momentum Equation [8].

That is, as shown in Figure 1, if the Momentum Loss Model that enables pressure drop to be proportional to the velocity of flow as in Equation (4) is applied to the gap area of door in the domain of the analytical model, the effect of the gap flow can be reflected.

$$
-\frac{\partial p}{\partial x_{i}}=K_{\text {loss }} \frac{\rho}{2}|u| u_{i}
$$

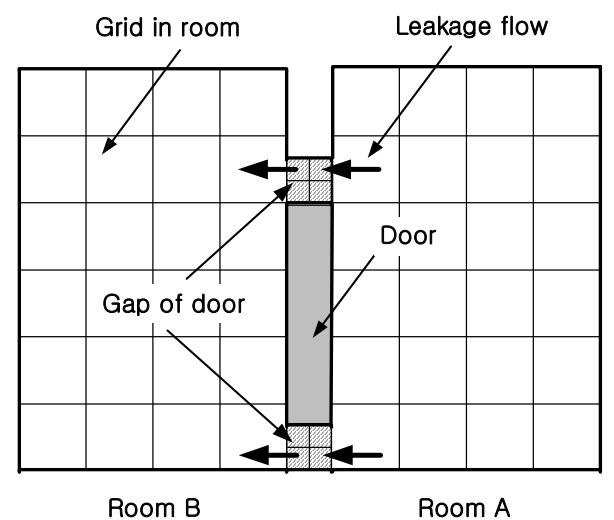

Figure 1. Schematic diagram about gap of door between rooms.

where $K_{\text {loss }}$ is a quadratic resistance coefficient.

$K_{\text {loss }}$ is a coefficient representing the characteristics of door gap, and a calculation can be made from the Orifice Equation of Equation (3) that contains experimental data and Momentum Loss Model of Equation (4).

In this study, a 3-dimensional flow analysis method that includes the leakage flow in the gap of the door was proposed using the Orifice Equation that is largely being applied to the gap flow analysis of buildings and Momentum Loss Model. In addition, a 3-dimensional numerical analysis of the stack effect on the stairs in buildings that include the gaps of doors was performed using this analysis method.

\section{Numerical Model of Leakage Flow through Gap of Door}

In this study, a 3-dimensional numerical analysis on the gap leakage flow of door that connect two rooms was performed first, and its characteristics were analyzed. For the applied pressure difference-leakage flowrate relation and geometric parameters, materials of representative publications [7] in the field of smoke design were used. As shown in Table 1, the door measures $2.1 \mathrm{~m}$ in height and $0.9 \mathrm{~m}$ in width, and the gap thickness at the top and side is $0.508 \mathrm{~mm}$, and that at the bottom $6.35 \mathrm{~mm}$. The relationship between pressure difference and leakage flowrate is determined by the Orifice Equation of Equation (2), and flow coefficient $C$ is 0.65 . Table 2 shows the pressure difference between rooms and corresponding flow rate of the gap leakage flow obtained from the major sections in relation to characteristics of the door.

Figure 2 shows the analytical model that includes two rooms and door. As shown in the figure, there exists the closed door between Room A with an air inlet and Room B with an air outlet. The air enters Room B through the gap of the door after entering the inlet of Room A and then goes to the outside through the outlet of Room B.

In numerical analysis, a calculation is performed by 
Table 1. Geometry of door.

\begin{tabular}{lcc}
\hline \multicolumn{2}{c}{ Design factor } & Value \\
\hline \multirow{2}{*}{ Door } & Width & $0.9 \mathrm{~m}$ \\
& Height & $2.1 \mathrm{~m}$ \\
Gap thickness & Top and sides & $0.508 \mathrm{~mm}$ \\
& Bottom & $6.35 \mathrm{~mm}$ \\
\multicolumn{2}{c}{ Door thickness $(\Delta L)$} & $0.2 \mathrm{~m}$ \\
Flow coefficient $(C)$ & 0.65 \\
\hline
\end{tabular}

Table 2. Flow rate induced by pressure difference through gap of door.

\begin{tabular}{cc}
\hline Pressure difference $(\mathrm{Pa})$ & Flow rate $\left(\mathrm{m}^{3} / \mathrm{s}\right)$ \\
\hline 10 & 0.022188807 \\
20 & 0.031379712 \\
30 & 0.038432142 \\
40 & 0.044377615 \\
50 & 0.049615682 \\
60 & 0.054351256 \\
\hline
\end{tabular}

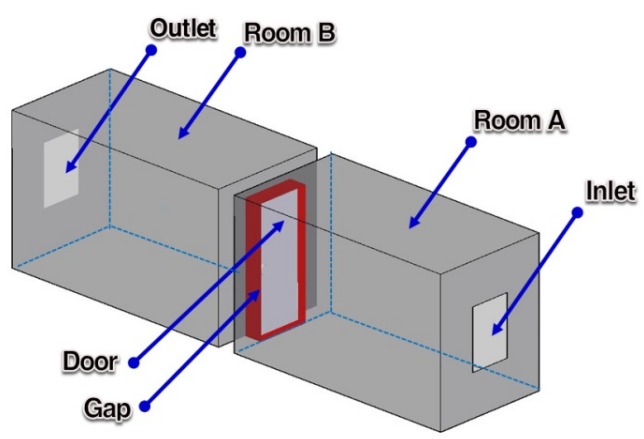

Figure 2. Analysis model of leakage flow at gap of door between rooms.

setting the leakage flow rate value of Table 2 to the input value of boundary condition on the inlet of Room A, and the pressure difference formed between Room A and Room B was investigated. In this study, the CFX14 [8], which has widely been used in thermal and flow analysis, was used due to its verification of the accuracy and validity as a numerical analysis program.

As mentioned earlier, the door gap flow was processed with the Momentum Loss Model in the numerical analysis, and $K_{\text {loss }}$, the quadratic resistance coefficient of Equation (4) can be derived as shown in Equation (5) by referring to the Orifice Equation of Equation (3).

$$
K_{\text {loss }}=\frac{2}{\rho} \frac{A_{m}^{2}}{\Delta L C_{t}^{2}}
$$

where $A_{m}$ is the area of the door gap in the numerical analysis model, $\Delta L$ is thickness of the door, and $C_{t}$ is coefficient in the Orifice Equation respectively.

Figure 3 shows the relationship of the leakage flow rate and pressure difference between rooms obtained by the Orifice Equation and numerical analysis. As shown in the figure, result values of the Orifice Equation and numerical analysis on the flow rate values were found to be almost identical, and the 3-dimensional numerical analysis model in which the Momentum Loss Model is applied was determined to show valid results with respect to the leakage flow of the gap.

\section{Effect of Separation Door in Stairwell}

As a part of methods to reduce stack effect on the stairs, there is a case where a door and a wall that separate the upper stairwell and lower stairwell are installed in the intermediate floor of the stairs.

In this study, a 3-dimensional numerical analysis of the stack effect on the stairs of buildings was performed using the Momentum Loss Model of the gap leakage flow which was reviewed, and the effect of the separation door was analyzed.

Figure 4 shows the analytical model of the stairs of buildings, the target of analysis. As shown in the figure, the number of stairs is 11 floors, and the height of each floor is $3 \mathrm{~m}$. A separation door was installed on the 6th floor to separate the upper stairwell and lower stairwell. Meanwhile, door and accommodation connected to the stairs were installed on the 1st and 11th floors, and

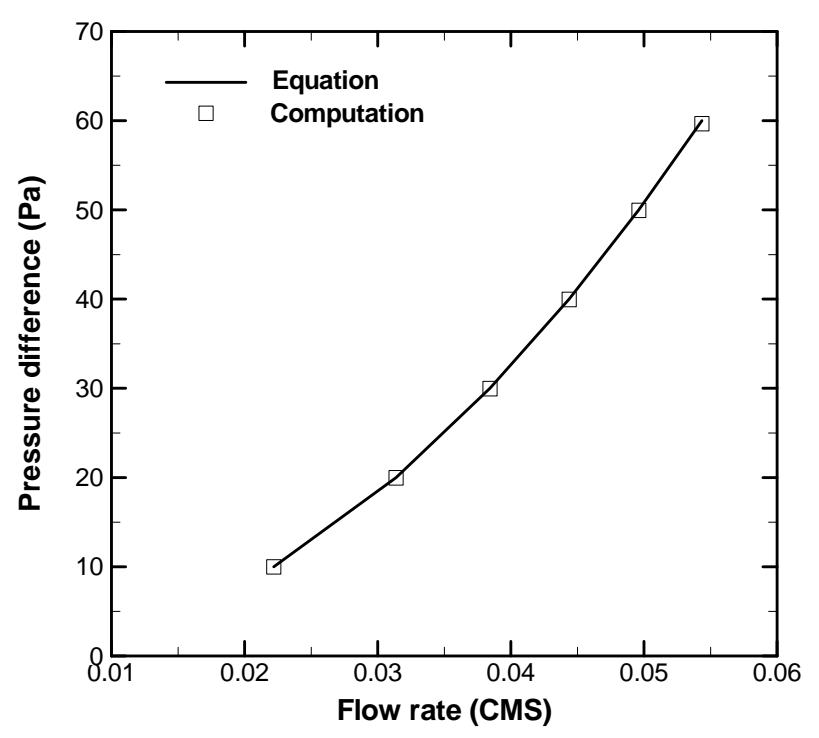

Figure 3. Pressure difference between rooms for leakage flow rate through gap of door. 


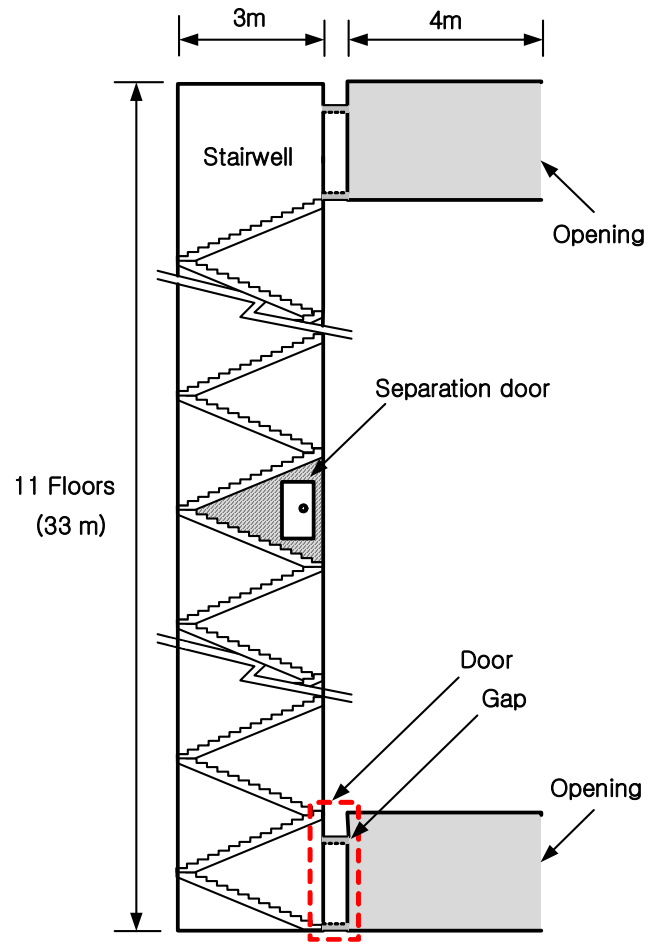

(a)

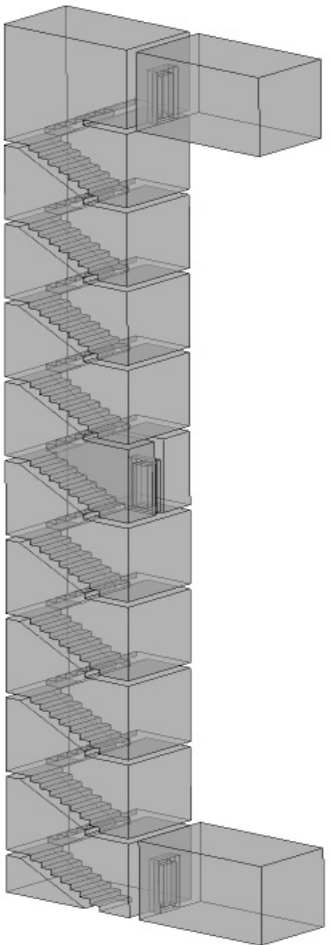

(b)

Figure 4. Analysis model of stairwell with separation door, (a) model of stairwell; (b) 3D model.

openings were made on one side of the room that comes in contact with the outside. In the door gap leakage floor, the Momentum Loss Model was applied. For analysis, the temperature of the stairs and room was set to $20^{\circ} \mathrm{C}$, and the outside temperature was set to $-10^{\circ} \mathrm{C}$.

Figure 5 shows the pressure distributions on the center plane of the stairs as results of analysis with and without the installation of the separation door. Figure 5(a) shows the result of analysis performed under a condition where there is no separation door. On the 1st floor stairwell, a negative pressure of about $-18 \mathrm{~Pa}$ is formed, and a positive pressure of about $20 \mathrm{~Pa}$ is formed on the 11th floor stairwell. Meanwhile, Figure 5(b) shows the result of analysis formed under a condition where there is a separation door. On the 1 st floor stairwell, a negative pressure of about $-10 \mathrm{~Pa}$ is formed, and a positive pressure of about $13 \mathrm{~Pa}$ is formed on the 11th floor stairwell. In addition, a positive pressure of about $3.5 \mathrm{~Pa}$ is formed on the 5th floor just below the separation door, and a negative pressure of about $-1.0 \mathrm{~Pa}$ is formed on the 7 th floor just above the separation door.

Figure 6 shows the result of numerical analysis performed by changing the gap area of the separation door. As shown in the figure, the less the gap area, the lower the pressure formed on the 11th stairwell and the higher the pressure formed on the 1st floor stairwell. Thus, it is adjudged that the gap area of the separation door has an effect on the stack effect on the stairs. In case of the leakage flow of the door gap due to the stack effect, as the gap area of the separation door decreases, flow rate is also reduced.

Based on the results of analysis, it can be inferred that the installation of separation door on the stairs of the building contribute to the reduction in the stack effect on the stairs to a certain extent, and the gap area of separation door has an effect on the amount of stack effect reduction.

\section{Effect of Lobby between Stair and Accommodation}

Meanwhile, there is a case where a lobby is installed between stair and accommodation as a part of the stack effect reduction methods.

In this study, a 3-dimensional numerical analysis on the stack effect was performed using the Momentum Loss Model after installing a lobby between stair and accommodation on the 1st and 11th floors with respect to the analytical model of the 11th stairwell presented earlier.

Figure 7 shows the pressure distribution on the center plane of the stairs as a result of analysis on the stack effect in a state where a lobby is installed. As shown in the figure, the pressure on the stairs is formed as the same result as in Figure 5(a) which shows the result obtained 


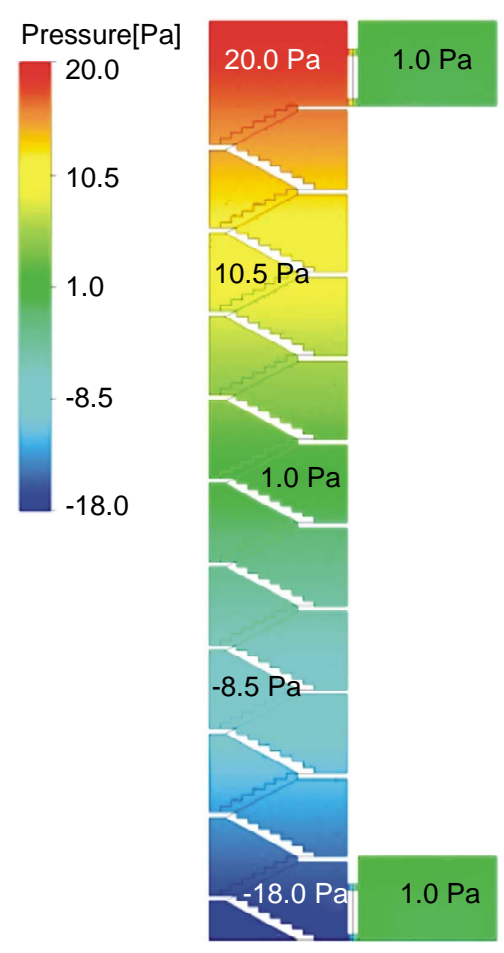

(a)

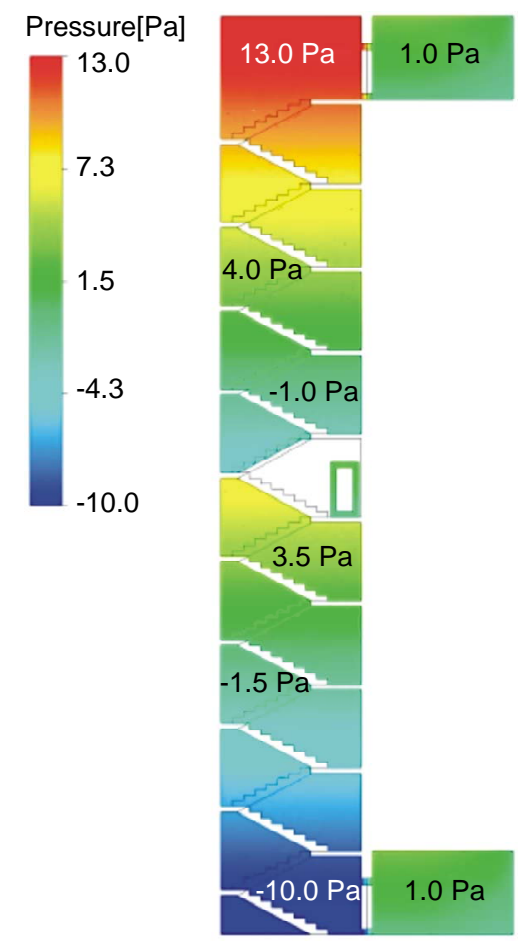

(b)

Figure 5. Pressure contours on center plane of stairwell in case of effect of separation door, (a) without separation door; (b) with separation door.

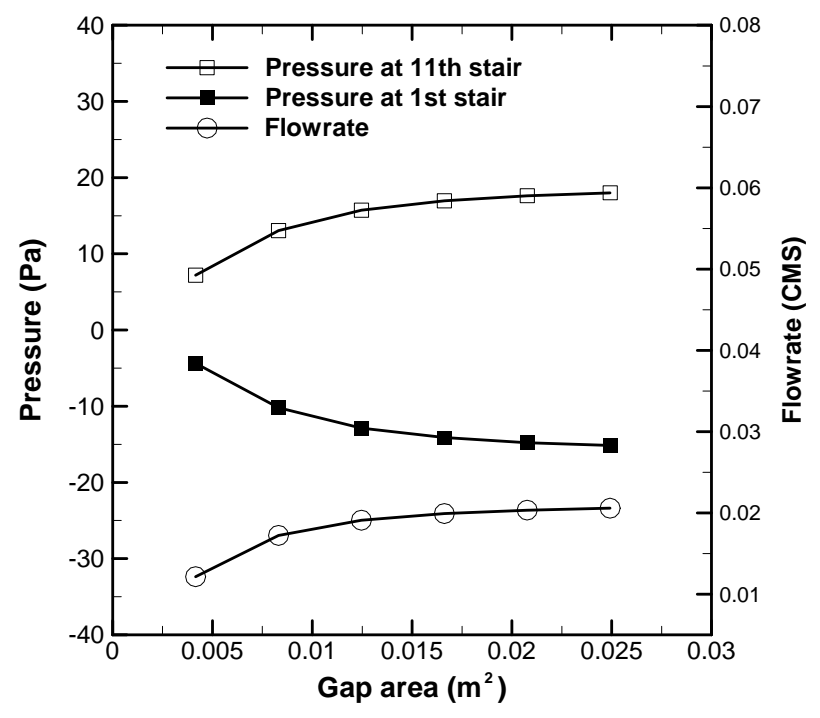

Figure 6. Pressure and flowrate for gap area in case of effect of separation door.

from case where a lobby is not installed. That is, the installation of a lobby does not contribute to the reduction in the stack effect on the stairs. Meanwhile, the pressure difference between rooms in the 1st and 11th floors was reduced considerably by installing a lobby. In case a lobby is not installed, the pressure difference between stair and accommodation of about $19 \mathrm{~Pa}$ is formed on the 1st floor. Whereas in case a lobby is installed, the pressure difference between stair and lobby of about $11 \mathrm{~Pa}$ is formed, and that between lobby and accommodation of about $8 \mathrm{~Pa}$ is formed respectively. As such, the installation of lobby between stair and accommodation leads to the reduction in the pressure difference between rooms due to the stack effect on each floor.

Figure 8 shows the results of numerical analysis performed by changing the door gap area between rooms. As shown in the figure, changes in the gap area of the door led to few changes in the pressure on the stair and lobby, and the leakage flow rate of the door gap was found to be increased linearly on the gap area.

\section{Conclusions}

In this study, a numerical analysis model was proposed with respect to the leakage flow through the gap of doors in buildings, and a 3-dimensional numerical analysis of the stack effect on the stairs of buildings was performed using the model. From the results, the following conclusions were derived.

1) In a 3-dimensional numerical analysis, the phenomenon of the gap flow can be reflected effectively through application of the Momentum Loss Model that enables the pressure drop to be proportional to the flow velocity through the gap of door.

2) As a result of the analysis on the two rooms in 


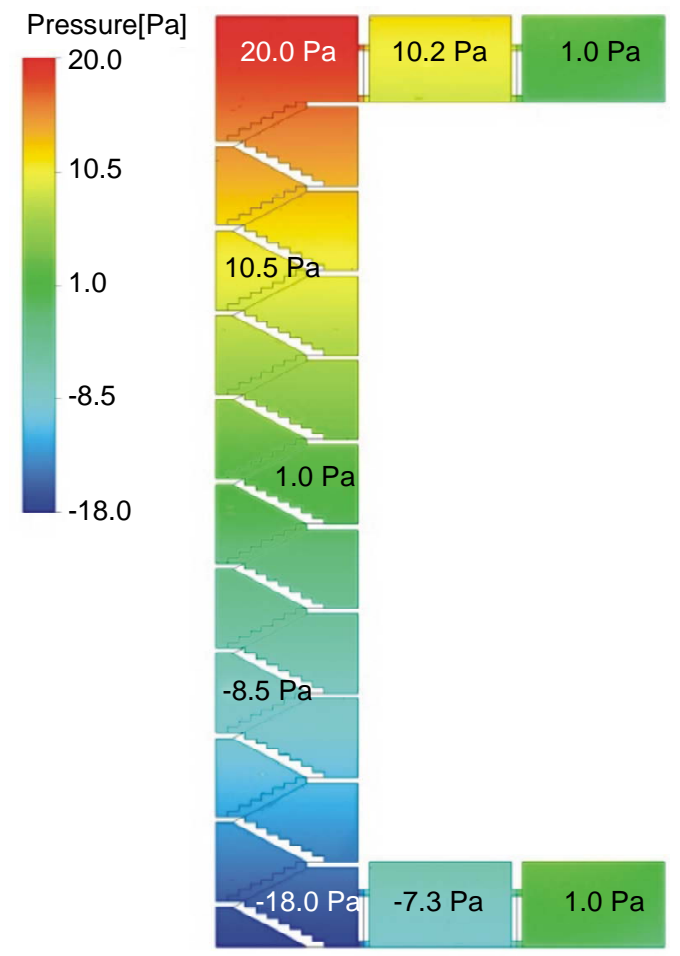

Figure 7. Pressure contours on center plane of stairwell in case of effect of lobby.

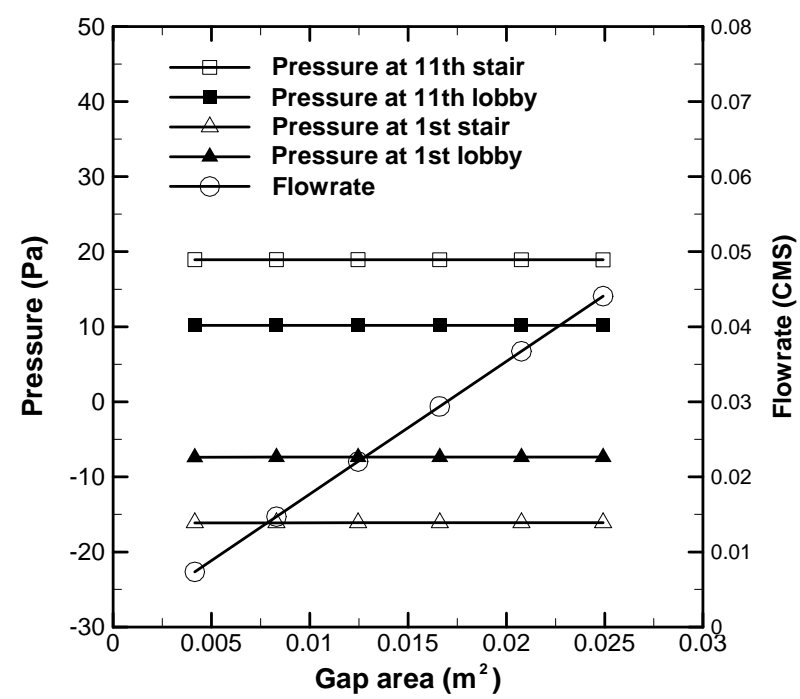

Figure 8. Pressure and flowrate for gap area in case of effect of lobby.

which a numerical model of the gap leakage flow is applied, it was found that the 3-dimensional numerical model in which the Momentum Loss Model is applied shows valid results since the results of the Orifice Equation and numerical analysis are almost identical with respect to the pressure difference corresponding to the given leakage flow rate.

3) The numerical analysis results of the stack effect on the stairs showed that a negative pressure of about -18 $\mathrm{Pa}$ is formed on the 1st floor stairwell, and a positive pressure of about $20 \mathrm{~Pa}$ on the 11th floor stairwell under the condition that the room temperature is $20^{\circ} \mathrm{C}$, and outside temperature is $-10^{\circ} \mathrm{C}$. Whereas, a negative pressure of about $-10 \mathrm{~Pa}$ is formed on the 1 st floor stairwell, and a positive pressure of about $13 \mathrm{~Pa}$ on the 11th floor stairwell under the condition that a separation door is installed on the stairs of buildings.

4) The installation of a separation door on the stairs of buildings contributes to the reduction in the stack effect on the stairs to a certain extent, and the gap area of the separation door has an effect on the amount of stack effect reduction.

5) The installation of a lobby between stair and accommodation doesn't lead to the reduction in the stack effect on the stairs. However, the pressure difference between rooms that occurs due to the stack effect on each floor is reduced.

\section{Acknowledgements}

This study has been conducted by the relevant study to “(2013) Development of smoke control/evacuation schemes and over 3-hour fire rated structural members in case of fire in large-space buildings" Project, a major project of Korea Institute of Construction Technology.

\section{REFERENCES}

[1] G. T. Tamura and A. G. Wilson, "Pressure Differences Caused by Chimney Effect in Three High Buildings," ASHRAE Transactions, Vol. 73, Part 2, 1967, pp. II.1.1II.1.10.

[2] J. H. Jo, J. H. Lim, S. Y. Song, M. S. Yeo and K. W. Kim, "Characteristics of Pressure Distribution and Solution to the Problems Caused by Stack Effect in High-Rise Residential Buildings," Building and Environment, Vol. 42, No. 1, 2007, pp. 263-277. http://dx.doi.org/10.1016/j.buildenv.2005.07.002

[3] H. Yang, M. S. Yeo, J. H. Jo and K. W. Kim, "Simulation of the Stack Effect in High-Rise Buildings," Journal of Air Conditioning and Refrigeration, Vol. 14, No. 6, 2002, pp. 456-467.

[4] D. W. Etheridge, "Crack Flow Equations and Scale Effect," Building and Environment, Vol. 12, No. 3, 1977, pp. 181-189.

http://dx.doi.org/10.1016/0360-1323(77)90016-6

[5] P. H. Baker, S. Sharples and I. C. Ward, "Air Flow through Cracks," Building and Environment, Vol. 22, No. 4, 1987, pp. 293-304. http://dx.doi.org/10.1016/0360-1323(87)90022-9

[6] D. Gross and W. L. Haberman, "Analysis and Prediction of Air Leakage through Door Assemblies," Fire Safety Science, Proceedings of the 2nd International Symposium, Tokyo, 13 June 1988, pp. 169-178. 
[7] J. H. Klote and J. A. Milke, "Principles of Smoke Management," American Society of Heating, Refrigerating and Air-Conditioning Engineers (ASHRAE), Atlanta, Society of Fire Protection Engineers (SFPE), Bethesda,
2002.

[8] ANSYS, Inc., “ANSYS CFX-Solver Theory Guide," ANSYS, Inc., Canonsburg, 2013. 